\title{
基于纳米碳的水伏材料及其能量转换器件
}

\author{
谭进 $^{1}$, 唐群委 ${ }^{2 *}$, 贺本林 ${ }^{1}$ \\ 1. 中国海洋大学材料科学与工程学院, 青岛 266100; \\ 2. 暨南大学新能源技术研究院, 广州 510632 \\ * 联系人, E-mail: tangqunwei@jnu.edu.cn
}

2018-04-19 收稿, 2018-06-03 修回, 2018-06-15 接受, 2018-07-12 网络版发表 国家自然科学基金 $(61774139,21503202,61604143)$ 、青岛海洋科学与技术国家实验室主任基金(QNLM201702)和中央高校基本科研业务费 (11618409)资助

\begin{abstract}
摘要如何收集和转化自然界巨大的水能资源是近年来研究的焦点. 自碳纳米管被发现具有在流水中产生电信 号的性质以来，以纳米碳为主的水伏材料因具有独特的“水生电”特性引起广泛的研究兴趣. 水能资源具有采集难 度低、存在范围广、储量丰富等特点, 主要以液态水、气态水两种形式存在.碳纳米管、石墨烯等纳米碳材料通 过双电层理论和电动理论捕获雨水、水流、波浪等液态水能，而具有多孔结构、高比表面积、氧浓度梯度的碳量 子点、碳黑、氧化石墨烯等则利用其独特的结构, 实现对气态水能的转化利用. 本文系统总结了纳米碳材料将液 态、气态水中蕴含的机械能、化学能转化为电能的研究进展以及其能量转换器件; 阐述了不同纳米碳和相关器件 对水能的转化原理, 并指出了水伏材料与器件发展过程中需要面对的挑战以及可能的发展方向.
\end{abstract}

关键词水伏材料与器件, 纳米碳材料, 流动电势, 能量捕获, 能量转换

如何解决能源危机与环境污染是人类正面临的 重大挑战, 开发可再生的清洁能源已成为全球范围 内的战略性选择. 发展低成本、高效率可再生能源转 化技术已成为世界各国能源发展的核心之一, 通过 提升核心技术与应用水平, 加快能源结构转型 ${ }^{[1 ~ 3]}$. 目前, 人们正通过对自然界中光能、风能、地热能、 水能等绿色能源的开发和利用逐步降低对煤炭、石 油、天然气等化石能源的依赖, 其中, 水能因其储量 大、分布广、无污染等优势表现出巨大的开发潜力和 应用价值 ${ }^{[46]}$. 已开发的水能资源包括河流水能、潮 汐能、波浪能、洋流能等多种形式, 依托堤坝、发电 机组等设施设备, 将水流中的机械能转化为电能.

传统的水能利用模式存在两大固有缺陷: (1) 水 能分布受水文、气候、地貌等自然条件的限制大, 容 易被地形、气候等外部因素所影响; (2) 大型设施设
备的建造和使用容易导致生态破坏和成本提升 ${ }^{[7 \sim 9]}$. 因此, 开发应用环境多样化、能量转化高效、发电成 本低廉的新型水伏材料与器件是对当前水能利用架 构的有效改善和补充. 随着纳米材料与技术的不断 进步，越来越多的纳米材料与器件被发现具有“水 伏”特性 ${ }^{[10 ~ 16]}$. 2003年, 单壁碳纳米管首次在实验中 被证实可以在流水中产生毫伏级的电势 ${ }^{[17]}$, 自此以 后, 多壁碳纳米管 ${ }^{[12]}$ 、集成的碳纳米管纤维 ${ }^{[18]}$ 等材料 相继被报道具有类似的性质，电压输出也从最初的 几毫伏提高到大于 $100 \mathrm{mV}$; 石墨烯的发现大大加速 了纳米碳水伏材料的发展, 包括单层石墨烯 ${ }^{[13]}$ 、氧化 石墨烯 ${ }^{[14]}$ 、石墨烯量子点 ${ }^{[19]}$ 在内的多种石墨烯及其 衍生物展现出独特的“水生电”特性. 经过十余年的 发展, 基于纳米碳的水伏材料种类越来越丰富, 器件 的电输出性能大大提高, 可以转化的水能形式也越 
来越多样(表1). 这些基于纳米碳的水伏材料与器件 可以与水中离子或水分子相互作用并在电极之间产 生电势差从而将水能直接转化为电能, 具有体积小、 转化效率高等特点, 可用于自然环境中的大功率水 能采集, 还可以应用于生活甚至人体中, 实现小功率 高灵活的水能转化 ${ }^{[27]}$. 本文系统总结了纳米碳的水 生伏特效应及其能量转换器件的研究进展, 概述了 对雨滴、水流、波浪、水蒸气等多种水能形态的捕获 过程和转化机理.

\section{1 水伏材料与器件对液态水能的转化}

\section{1 一维碳纳米管系}

碳纳米管用于流体发电的研究始于2001年, Král 和Shapiro ${ }^{[28]}$ 通过理论计算提出流体在碳纳米管表面 运动引起的声子纠缠拖曳自由载流子在碳纳米管中 定向移动产生电流; 2003年, Ghosh等人 ${ }^{[17]}$ 开发了碳 纳米管流量传感器, 首次通过实验验证了碳纳米管 在水流作用下的发电特性. 实验结果表明, 碳纳米管 在水流速度为 $1.8 \times 10^{-3} \mathrm{~m} / \mathrm{s}$ 时可产生 $2.67 \mathrm{mV}$ 的诱导 电压, 并且输出电压随着水流速度的增加呈指数上 升(图 1(a)); 并进一步提出了一维周期性电势理论, 认为固-液界面处的流速梯度导致了电荷的不均衡分 布从而产生了电势差, 这项工作推动了纳米碳材料 在流体中发电的研究 ${ }^{[30,31]}$. 但应当指出的是, 该项工 作采用尺寸为 $(0.1 \times 0.2) \mathrm{cm}^{2}$ 的单壁碳纳米管薄膜, 并 将 2 个裸露的金属电极连接在样品两端, 因此当液体
流经样品时, 金属电极也同时暴露在液体中与液体 产生直接接触; 后续的研究表明 ${ }^{[32]}$ : 暴露在液体中 的金属电极与流动的液体相互作用会在两电极间产 生电势差且该电势差会随流体流速变化而改变, 石 墨烯和碳纳米管在这个过程中更多的是作为负载而 存在，因此该实验中样品在流体中产生的电信号很 可能和金属电极与流体的相互作用有关.

早期的碳纳米管基流体发电器件由于体积小、结 构单一而导致输出功率较低, 研究具有特殊结构、集 成度高的碳纳米管水伏器件能有效提高功率输出, 复旦大学彭慧胜研究组 ${ }^{[27,33]}$ 利用碳纳米管优良的导 电性和高抗拉强度, 构建了一种质轻、柔性且可拉伸 的纤维状流体纳米发电机 ${ }^{[18]}$, 可高效收集环境和人 体中各种流动液体的能量, 能量转化效率高达 $23.3 \%$ (图 1(d)). 多壁碳纳米管在水中的zeta电位为 $-12.5 \mathrm{mV}$, 将其浸人盐溶液后, 盐溶液中的阳离子 吸附在多壁碳纳米管表面形成吸附层, 而盐溶液电 离产生的阴离子对阳离子的中和过程相对迟缓, 在 吸附层外部形成扩散层，从而构成了双电层结构(图 1(b)). 碳纳米管与盐溶液接触时, 吸附层阳离子静电 吸附碳纳米管表面的电子; 当盐溶液与纤维状纳米 发电机表面发生相对位移时, 多壁碳纳米管两端的 电子分布不均, 产生了电势差. 随着水流速度降低, 输出的电信号强度也随之降低, 并当流速为 0 时, 电 输出并没有消失, 研究者认为这与金属-纳米碳结的 电性质有关 ${ }^{[34]}$. 除了具有超高的能量转化效率之外, 该纤维状流体纳米发电机同时具有优异的长期稳定

\section{表 1 基于纳米碳的水伏材料与器件汇总表}

Table 1 Summary of water-enabled electricity generation devices from carbon nanomaterials

\begin{tabular}{|c|c|c|c|c|c|}
\hline 年份 & 碳材料 & 水体系 & 电压 & 电流 & 文献 \\
\hline 2003 & 单壁碳纳米管 & 水/甘油、 $\mathrm{HCl}$ 水溶液 & $\sim 2.67 \mathrm{mV}$ & - & [17] \\
\hline 2007 & 多壁碳纳米管 & $\mathrm{NaCl}$ 水溶液 & $\sim 30 \mathrm{mV}$ & - & {$[12]$} \\
\hline 2008 & 单壁碳纳米管 & 水蒸气 & - & $\sim 8.10 \mathrm{nA}$ & [20] \\
\hline 2014 & 单层石墨烯 & 盐溶液 & $\sim 0.15 \mathrm{mV}$ & - & [21] \\
\hline 2016 & 碳黑薄膜 & 水蒸气 & $68 \mathrm{mV}$ & - & {$[22]$} \\
\hline 2016 & 氧化石墨烯 & 水蒸气 & $0.26 \mathrm{~V}$ & $3.2 \mathrm{~mA} / \mathrm{cm}^{2}$ & [23] \\
\hline 2016 & 还原的氧化石墨烯 & 模拟雨水 & $109.26 \mu \mathrm{A}$ & $0.49 \mu \mathrm{A}$ & [24] \\
\hline 2017 & 集成的多壁碳纳米管 & 盐溶液 & $>100 \mathrm{mV}$ & - & [18] \\
\hline 2017 & 碳黑薄膜 & 水蒸发 & $0.85 \mathrm{~V}$ & - & [25] \\
\hline 2017 & 石墨烯量子点 & 水蒸气 & $0.27 \mathrm{~V}$ & $24 \mathrm{~mA} / \mathrm{cm}^{2}$ & [19] \\
\hline 2018 & 石墨烯-碳黑/聚氨酯 & 海水 & $11.14 \mathrm{mV}$ & $3.00 \mu \mathrm{A}$ & [26] \\
\hline
\end{tabular}



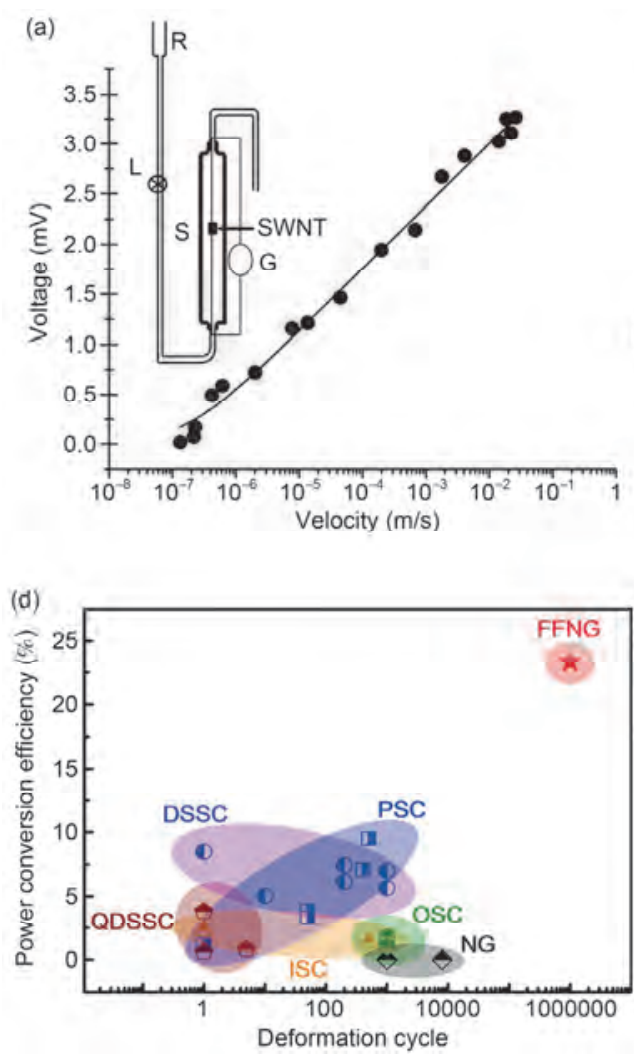

(b)

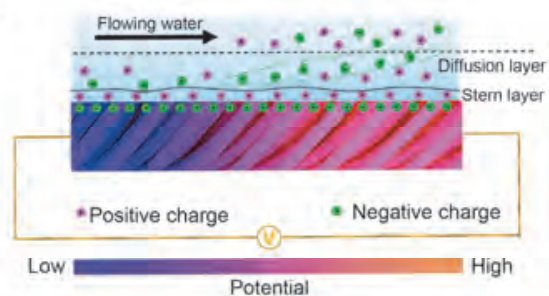

(c)

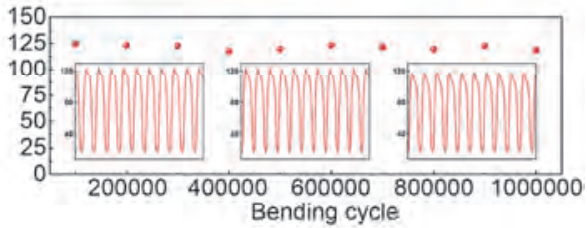

(e)

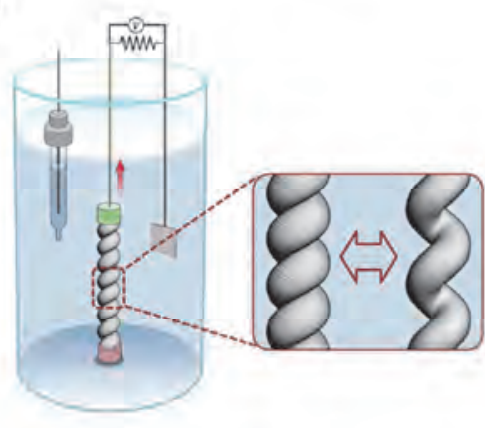

图 1 (网络版彩色)(a) 一维碳纳米管在不同流速水流刺激下的电压输出 ${ }^{[17]}$; (b) 纤维状流体纳米发电机(FFNG)的结构和工作原理示意图; (c) 纤维状流体纳米发电机经多次拉伸/释放循环过程的电压输出; (d) 纤维状流体纳米发电机与其他纤维状电池的能量转化效率对比图 ${ }^{[18]}$; (e) 螺 旋结构的“Twistron”纱线在盐溶液浸泡下拉伸发电示意图 ${ }^{[29]}$

Figure 1 (Color online) (a) The voltage output of one-dimensional carbon nanotubes under different flow velocities ${ }^{[17]}$. (b) Schematic illustration to the working mechanism of the generated flowing potential in the FFNG. (c) Output voltage generated by repeatedly dipping an FFNG into a NaCl solution with an increasing number of bending cycles. (d) Power conversion efficiencies and flexibilities of the FFNG and other fiber-shaped generators $^{[18]}$. (e) Illustration of "Twistron" yarn with a spiral structure harvesting energy in saline solution ${ }^{[29]}$

性和耐久性, 在历经十万次形变后, 依然可以保持很 好的性能(图1(c)); 通过对器件的串并联可以将电输 出成倍增加, 12 个纤维基流体纳米发电机串联后峰值 电压可达 $2.3 \mathrm{~V}$, 并联后峰电流为 $0.34 \mathrm{~mA}$, 这表明器 件可以通过规模化集成实现大功率的水能捕获. 另 外, 由于具有独特的一维结构, 这类纤维状流体纳米 发电机有望植人人体, 收集血液的能量, 为发展高效 和小型化的能源系统提供了新途径.

利用碳纳米管包覆聚合物基底可构建具有碳纳 米管薄层结构的纤维状流体纳米发电机, 在薄层和 盐溶液的固-液界面处形成双电层从而产生电势差. 美国德克萨斯大学达拉斯分校和韩国汉阳大学研究 人员 ${ }^{[29]}$ 提出了另一种具有独特结构的“Twistron”纱 线, 它由许多根碳纳米管纺成, 为了提高纱线弹性, 研究人员不断提高纱线的捻度, 使纱线呈类似弹簧 的螺旋结构(图1(e)). “Twistron”本质上是一种不需要
外加电源的电容器, 当它在盐溶液中被拉伸或扭转 时, 碳纳米管纱线的扭转度增加, 使纱线密度增加, 将导致碳纳米管的电容性降低, 并因此产生开路电 压, 释放纱线则产生相反的电荷传输过程. 通过碳纳 米管纱线的反复拉伸/释放循环, “Twistron”可将流体 中的机械能转化为电能, 若在 $0.1 \mathrm{~mol} / \mathrm{L}$ 的 $\mathrm{HCl}$ 水溶液 中以 $0.1 \mathrm{~Hz}$ 的频率对其拉伸, 机械能-电能转换效率 为 $1.05 \%$; 研究人员同时测试了“Twistron”在海水中 发电的可行性，波浪的运动最高可使纱线的拉伸率 达到 $25 \%$, 基于目前的平均输出功率, 只需要 $31 \mathrm{mg}$ 的“Twistron”纱线就可以在 $100 \mathrm{~m}$ 半径范围内提供每 10 s传输 2000 字节数据所需的电能.

\section{2 二维石墨烯系}

单层石墨烯是自然界中已知最薄的二维片层材 料, 碳原子以 $\mathrm{sp}^{2}$ 杂化轨道组成六角型蜂巢状晶格, 
每个碳原子垂直于层平面的 $\mathrm{p}_{z}$ 轨道可以形成贯穿全 层的多原子的大 $\pi$ 键, 这种碳原子键合和排布方式与 一维碳纳米管类似, 因此在理论上应具有与碳纳米 管相似的流体电动性质 ${ }^{[35 ~ 38]}$. 2014年, 南京航空航天 大学郭万林团队 ${ }^{[21]}$ 首次报道了盐溶液液滴在单层石 墨烯表面移动可以产生电信号. 如图2(a)所示, 0.6 $\mathrm{mol} / \mathrm{L} \mathrm{NaCl}$ 水溶液液滴在单层石墨烯上以 $2.25 \mathrm{~cm} / \mathrm{s}$ 的速度滑动可以产生 $0.15 \mathrm{mV}$ 的电压, 滑动方向相反 则产生不同方向的电压信号(图2(b)), 当液滴静止时 则没有流动电势产生. 基于上述实验结果, 郭万林研 究组 ${ }^{[32]}$ 提出了双电层赝电容理论: 根据密度泛函理 论计算(图2(c)), 盐溶液液滴中的 $\mathrm{Na}^{+}$离子与石墨烯 的表面电子之间具有 $2 \mathrm{eV}$ 的吸附能; 当液滴与石墨 烯表面接触时, $\mathrm{Na}^{+}$被吸附在石墨烯表面, 石墨烯中 电子受到 $\mathrm{Na}^{+}$吸引在石墨烯表面产生富集, 随着被吸 附 $\mathrm{Na}^{+}$浓度的增加, 电子在石墨烯表面聚集形成电子 层, 与 $\mathrm{Na}^{+}$吸附层构成双电层㕍电容; 当液滴静止时, 石墨烯-液滴界面两端电荷平衡分布, 此时液滴的左
右两端不存在电势差; 当液滴在石墨烯表面发生相 对位移时, 位移方向前端液滴中 $\mathrm{Na}^{+}$离子吸附石墨烯 表面的电子, 使赝电容充电并产生高电势; 相反, 液 滴后端 $\mathrm{Na}^{+}$离子脱附, 石墨烯表层被吸附电子回到原 位, 使赝电容放电并产生低电势, 液滴前后两端的电 势差是输出电能的根本原因. 利用这种独特的水伏 特性, 研究人员研制成功一种书写感应器件(图2(d)), 可以通过输出电信号的正负和大小判断书写的方向 和速度; 在能源采集方面, 这项工作开创性地发现了 液态水在二维碳材料表面滑动输出电能的现象, 为 大面积捕获雨水、海水等液态水中蕴含的能量提供了 可能.

随后, 郭万林课题组 ${ }^{[39]}$ 报道了二维石墨烯在盐 溶液中产生波动电势的工作. 如图 3(a)所示, 在0.6 $\mathrm{mol} / \mathrm{L} \mathrm{NaCl}$ 水溶液中快速的浸人、拔出单层石墨烯片 将产生波动电势(图3(a), (b)); 单个尺寸为 $(2 \times 10) \mathrm{cm}^{2}$ 的单层石墨烯在插人速度为 $1 \mathrm{~m} / \mathrm{s}$ 时可产生最高 $0.1 \mathrm{~V}$ 的电压和 $11 \mu \mathrm{A}$ 的电流, 电信号的产生主要归因于双 (a)

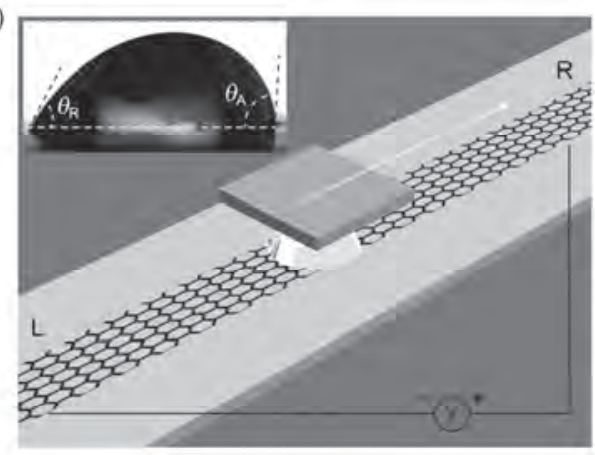

(c)

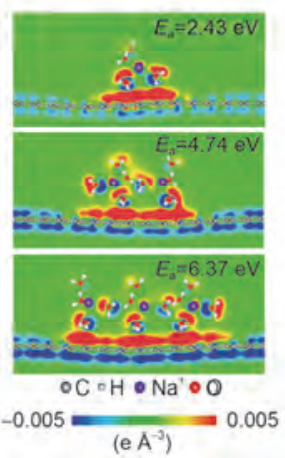

(b)

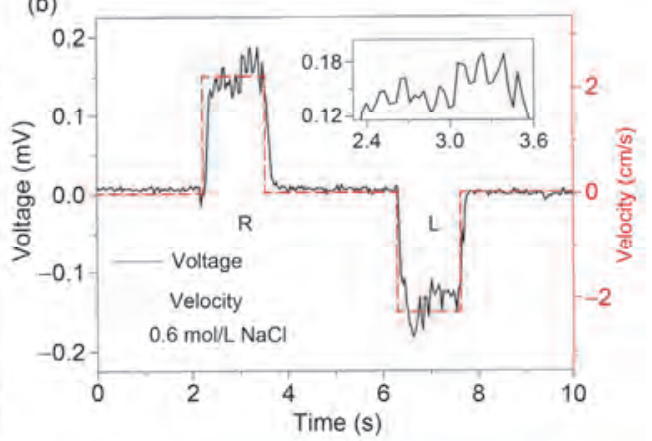

(d)

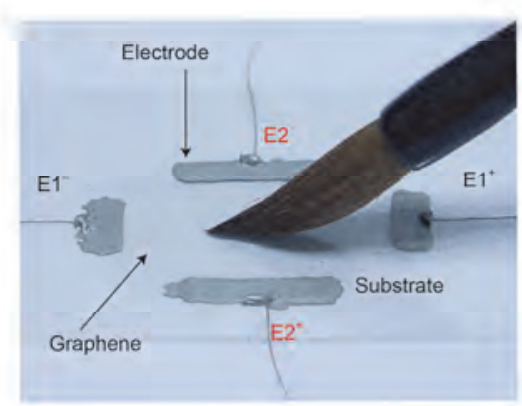

图 2 (网络版彩色)(a) $\mathrm{NaCl}$ 水溶液在单层石墨烯表面滑动输出电能的示意图; (b) $0.6 \mathrm{~mol} / \mathrm{L} \mathrm{NaCl}$ 水溶液液滴在单层石墨烯表面滑动产生电压; (c) 基于密度函变理论模拟发电过程中的离子排布及赝电容形成过程; (d) 书写感应器件示意图 ${ }^{[21]}$

Figure 2 (Color online) (a) The schematic of generating electricity by moving a droplet of $0.6 \mathrm{~mol} / \mathrm{L} \mathrm{NaCl}$ solution along graphene. (b) Voltage signal produced by drawing a droplet on a graphene strip from different direction. (c) Density functional theory (DFT) results for the distribution of charges at graphene/solution interface as well as the forming process of pseudocapacitance. (d) Photograph of handwriting with a Chinese brush on graphene ${ }^{[21]}$ 
(a)

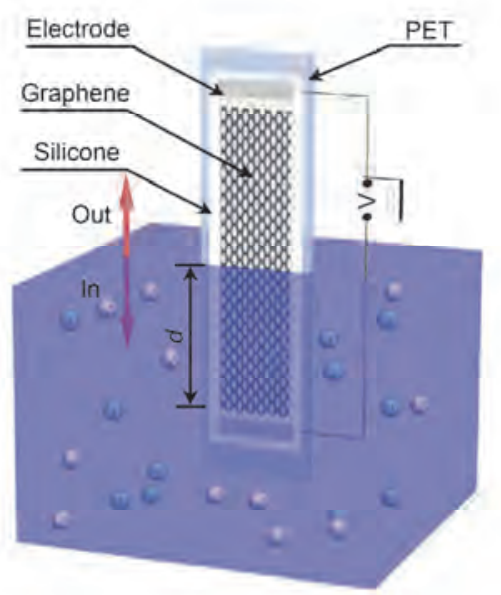

(c)
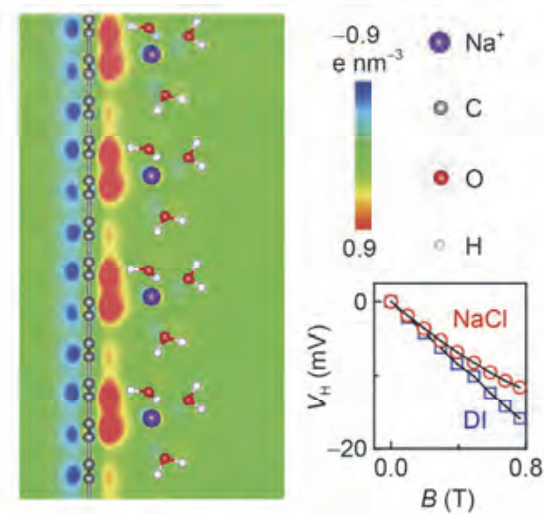

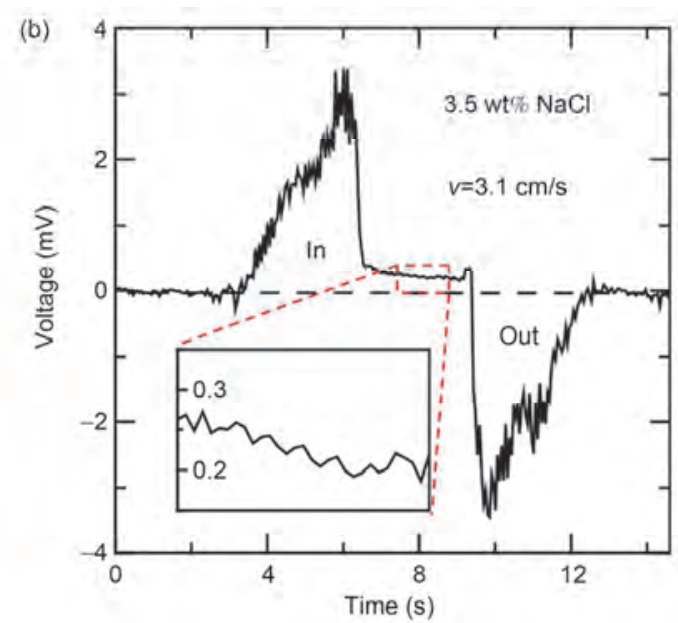

(d)

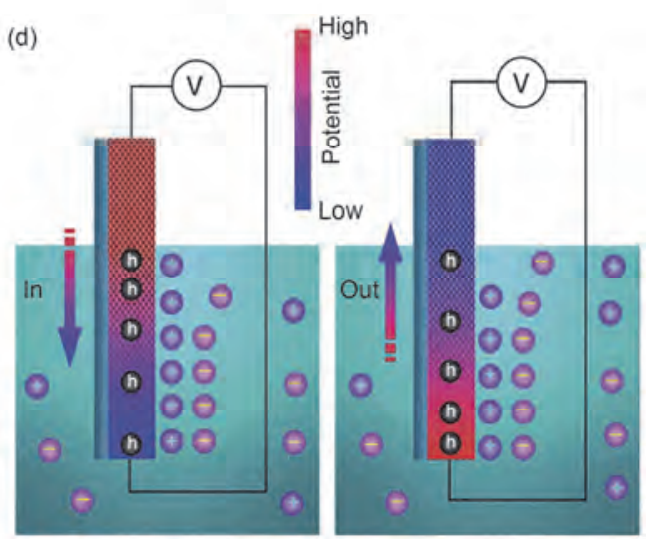

图 3 (网络版彩色)(a) 单层石墨烯快速浸人/拨出盐溶液用于电能捕获的示意图; (b) 单层石墨烯浸人和拔出 $3.5 \%$ (质量百分比) NaCl水溶液产 生相反的电压信号; (c) 根据密度函变理论模拟的石墨烯表面吸附 $\mathrm{Na}^{+}$的分布; (d) 浸人/拔出石墨烯过程中双电层形成及双电层边界移动示意 图 ${ }^{[39]}$

Figure 3 (Color online) (a) The schematic of generating electricity by immersing/pulling out monolayer graphene in saline solution. (b) Voltage signals produced as a sample is inserted and pulled out of $3.5 \mathrm{wt} \% \mathrm{NaCl}$ solution. (c) Distribution of charges upon graphene surface calculated by DFT. (d) Illustration of the electrical double layer (EDL) forming and EDL boundary movement during the process immersing/pulling out monolayer graphene in saline solution ${ }^{[39]}$

电层边界的移动. 由于 $\mathrm{Na}^{+}$离子与石墨烯之间具有较 高吸附能, 当单层石墨烯浸人盐溶液中时, $\mathrm{Na}^{+}$离子 被吸附到石墨烯表面, 带负电的 $\mathrm{Cl}^{-}$运动较迟缓不能 立刻中和 $\mathrm{Na}^{+}$电荷, 因此带正电的 $\mathrm{Na}^{+}$离子吸引石墨 烯中的电子形成双电层结构, 并在石墨烯内部留下 空穴(图3(d)); 盐溶液/空气间的液-气双电层边界处 被石墨烯吸附的 $\mathrm{Na}^{+}$离子数量多, 相应的电子和空穴 浓度也较高, 浸泡在盐溶液以下部分由于 $\mathrm{Cl}^{-}$对 $\mathrm{Na}^{+}$ 的中和, 使石墨烯表层电子被释放回归原位与空穴 复合, 相应的电子和空穴浓度降低, 由此产生的单层 石墨烯两端电子和空穴的浓度差导致了电信号的产 生; 当把单层石墨烯从盐溶液中拔出时, 液-气双电 层边界向下移动, 产生方向相反的电信号(图3(b)).
此外，电信号强度依赖于石墨烯的浸入/拔出速度以 及盐溶液种类：浸人/拔出速度越快, 被 $\mathrm{Cl}^{-}$中和的 $\mathrm{Na}^{+}$越少, 双电层边界处电子、空穴浓度也越高, 由 此产生的电信号越强; 若盐溶液中阳离子半径越小, 石墨烯能够吸附更多小半径阳离子, 当双电层边界 移动时, 小半径阳离子的迁移也更加灵活并产生更 强的电信号. 相比于盐溶液液滴在单层石墨烯表面 的运动, 这种流体与石墨烯之间发生相对位移产生 的电信号明显提升, 对有效捕获和转化包括水流、波 浪在内的波动式运动液态水水能具有重要意义.

雨是自然界中液态水的一种重要存在形式, 长 期以来, 雨中的水能未能得到有效开发和利用, 石墨 烯在流体发电方面表现出的独特性质让雨水发电成 
为可能. 雨水中含有丰富的 $\mathrm{Na}^{+}, \mathrm{NH}_{4}{ }^{+}, \mathrm{Ca}^{2+}, \mathrm{Mg}^{2+}$ 等 阳离子和 $\mathrm{Cl}^{-}, \mathrm{NO}_{3}^{-}, \mathrm{SO}_{4}^{2-}$ 等阴离子, 当雨水滴落在石 墨烯表面时, 可以通过构建阳离子/电子的双电层赝 电容结构使其在滑落过程中完成充放电产生电能. 本课题组 ${ }^{[40]}$ 制备了一种疏水的石墨烯-碳黑/聚四氟 乙烯复合导电薄膜, 在保留单层石墨烯原有“滴水生 电” ”性能的基础上, 提高复合涂料的成膜性、降低高 成本的石墨烯用量, 实现了对雨水能的收集. 当雨滴 滴落在石墨烯-碳黑/聚四氟乙烯复合导电薄膜上时, 雨水中的阳离子与石墨烯的表面电子结合形成双电 层赝电容(图4(a)). 由于薄膜的疏水性, 雨滴在重力 作用下滴落在薄膜表面发生铺展-收缩过程, 雨滴铺 展外扩使阳离子吸附更多电子, 完成赝电容的充电; 收缩过程使阳离子解吸, 释放表层电子回到原位, 使 赝电容放电, 在充放电过程实现了雨水能向电能的 转化. 调控石墨烯-碳黑/聚四氟乙烯复合导电薄膜中 石墨烯-炭黑的含量可以使薄膜欧姆电阻随之改变, 欧姆电阻与石墨烯-炭黑的含量间呈现渗率现象 (图 4(b)). 与绢云母在复合薄膜中形成的交联网状结构 类似(图4(c)), 石墨烯、炭黑等导电物质会随着含量的 增加在薄膜中逐渐交联成网, 在某一阈值处呈现出 欧姆电阻的突然下降, 大大降低了电子在薄膜中传 输的阻力, 电压、电流信号也因此体现出相应的渗率 规律(图4(d), (e)). 这种基于纳米碳材料/聚合物的导 电复合薄膜在不影响电功率输出的情况下, 用成本 较低的碳黑、聚合物部分取代成本高昂的石墨烯, 不 仅大大降低了器件成本, 而且改善了碳纳米材料的 成膜性, 对“滴水生电”走向实用具有重要价值, 这种 复合导电薄膜的设计思路对降低其他水伏器件成本、 提高器件实用性方面同样具有指导意义.

海洋占地球表面积的 $71 \%$, 蕴含着巨大的海洋 能资源, 而波浪能是最主要的海洋能存在形式之一. 联合国教科文组织出版的《海洋能开发》表明, 全球 波浪能的理论可再生功率达 10 亿 $\mathrm{kW}$, 如何高效捕获 和转化波浪能成为水能开发利用的研究重点 ${ }^{[7,41]}$. 在 前期工作基础上 ${ }^{[39,40]}$, 本课题组 ${ }^{[26]}$ 基于电动理论首 次设计开发了一种薄膜类波浪能转化器件, 该器件 以碳黑、石墨烯、水性聚氨酯为主要原料, 通过调节 碳黑-石墨烯含量获得最优配比的波浪能转化器件并 产生最大电压 $11.14 \mathrm{mV}$ 和最大电流 $3.00 \mu \mathrm{A}$ 的脉冲信 号, 包括浪速、水温、器件放置倾斜角在内的多种实 际参数都会对器件电信号输出产生影响. 如图 5 所示,
当海水冲刷器件表面时, 海水中的 $\mathrm{Na}^{+}$等阳离子吸附 在石墨烯表面, 与石墨烯表面电子形成双电层结构, 海水与薄膜底部接触时的速度较快. 此时, 液-气界面 双电层边界处被吸附的电子浓度很高; 海水继续向 上冲刷时, 双电层边界上移, 在新的边界处富集电 子, 由于器件存在一定的倾斜角, 冲刷速度会随着水 温高度增加而降低, 这使得被海水没过的薄膜底部 $\mathrm{Na}^{+}$部分被 $\mathrm{Cl}^{-}$中和, 释放了相应被吸附的电子回归 原位, 总的电子浓度仍然高于上一阶段; 当海水冲刷 到薄膜顶端开始回落时, 波浪速度为 0 , 此时被海水 没过的整个薄膜上外部 $\mathrm{Na}^{+}$被 $\mathrm{Cl}^{-}$严重中和, 大量被 吸附电子回归原位, 使电子浓度降低; 由于薄膜的部 分亲水性, 海水下降后会在薄膜表面留下一层水膜 并逐渐收缩, 这层水膜的存在干扰了双电层边界的 形成, 因此在海水回落过程中并没有产生方向相反 的电信号. 这项工作基于电动理论, 通过制备薄膜型 海洋波浪能转化器件实现了对各种频率波浪能的直 接转化, 从根本上避免了传统电磁波浪能转化设备 因波浪随机性造成的发电效率低、电输出不稳定等问 题; 简单的器件结构也避免了大型钢铁设备的使用, 极大降低了制造和维护成本, 对于提高波浪能转化 效率、降低发电成本具有重要意义.

\section{3 二维碳黑薄膜系}

液态水的蒸发是形成自然界水循环的关键过程 并释放出能量巨大的水能. 华中科技大学周军研究组 和南京航空航天大学郭万林研究组 ${ }^{[25]}$ 首先发现了水 蒸发驱动碳黑薄膜发电的现象, 薄膜由粒径为 $20 \mathrm{~nm}$ 的碳黑纳米微粒构成, 经过退火和等离子处理之后 呈亲水性. 当把这种碳黑薄膜部分浸人到去离子水 中时, 水分子和多孔碳膜相互作用产生自下而上逐 渐增大的电压, 电压最高可达 $1 \mathrm{~V}$ 并可维持 $8 \mathrm{~d}$ (图 $6(d))$. 研究人员发现, 完全没在水下或完全暴露在空 气中的碳黑薄膜都不能产生电信号, 同时电信号也 会因水蒸发程度的降低而呈下降趋势. 这些现象说 明, 电信号的产生与水蒸发过程, 尤其是与蒸发产生 的水蒸气流在含有亲水基团的多孔碳膜内的运动过 程有关. 根据密度泛函理论计算, 蒸发产生的水分子 与纳米碳黑微粒间产生独特的双电层结构, 电子的 重新分布导致了电动现象的产生. 但是, 电信号产生 的确切机理还不够清楚, 需要后续工作进一步讨论. 研究人员通过串并联实现了电输出的成倍增加, 4 个 
(a)

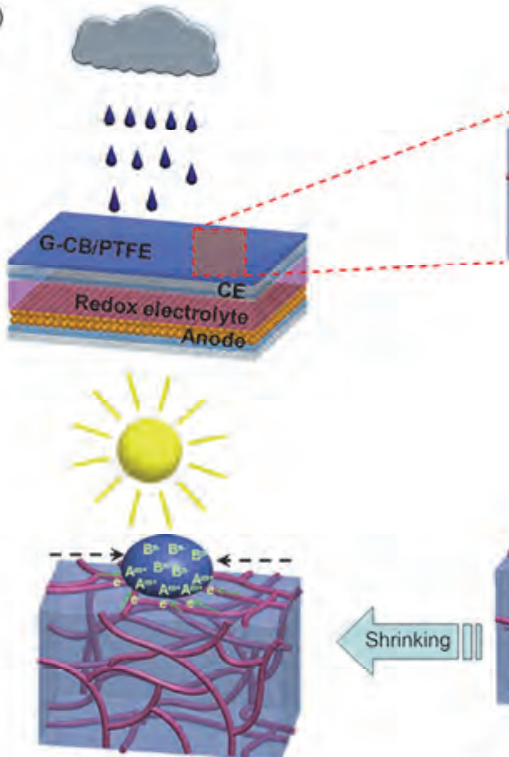

(v)
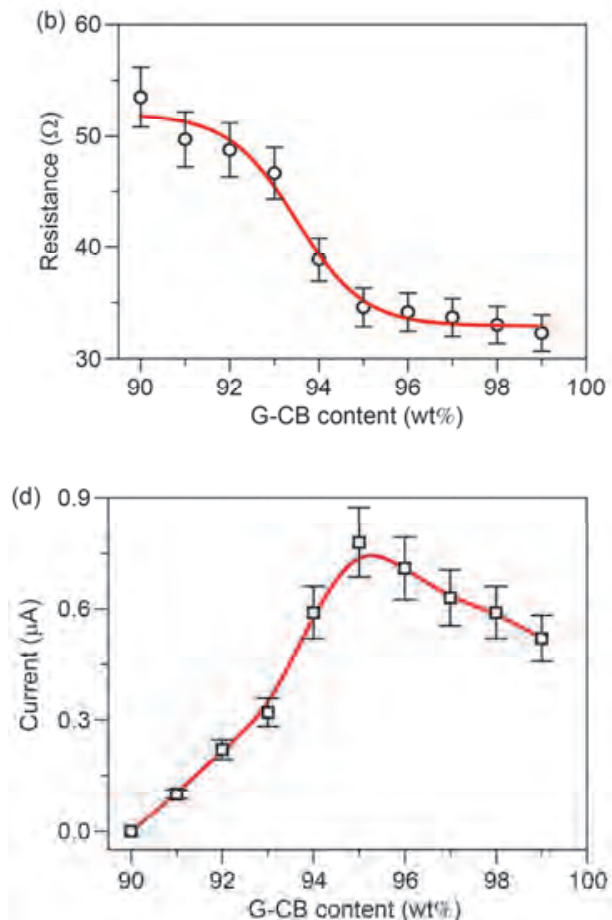

(c)

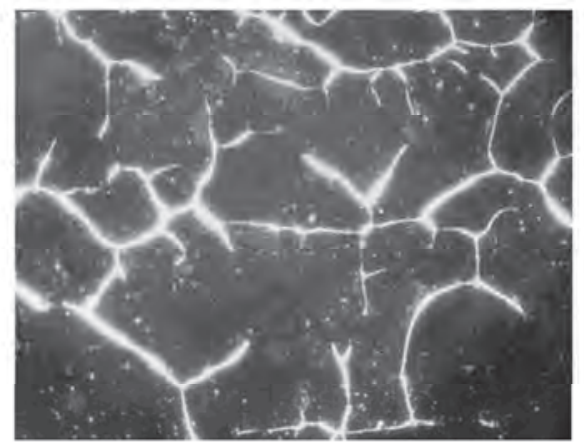

(e)

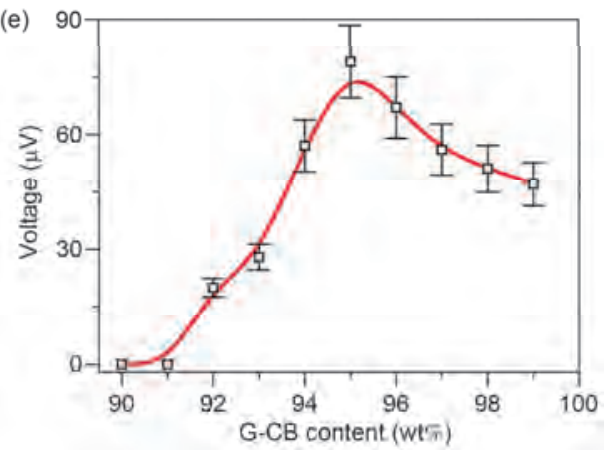

图 4 (网络版彩色)(a) 雨滴在石墨烯-碳黑/聚四氟乙烯(G-CB/PTFE)导电薄膜表面铺展/收缩过程中电荷的传输示意图; (b) 导电薄膜的欧姆电 阻与石墨烯-碳黑含量的关系曲线; (c) 聚丙烯酸/绢云母复合薄膜的偏光显微镜照片; $0.6 \mathrm{~mol} / \mathrm{L} \mathrm{NaCl}$ 水溶液液滴在石墨烯-碳黑/聚四氟乙烯导 电薄膜表面产生的电流(d)和电压(e)与石墨烯-碳黑含量的关系图 ${ }^{[40]}$

Figure 4 (Color online) (a) Illustration of charge transfer during the spreading/shrinking processes for a raindrop on G-CB/PTFE conducting composite. (b) The sheet resistance evolution of G-CB/PTFE conducting composites. (c) The polarizing microscopic image of polyacrylate/sericite composite. Current (d) and voltage (e) signals created by dropping $0.6 \mathrm{~mol} / \mathrm{L} \mathrm{NaCl}$ aqueous solution on G-CB/PTFE film ${ }^{[40]}$

器件串联可以得 $4.8 \mathrm{~V}$ 的电压和 $380 \mathrm{nA}$ 的电流, 足以 点亮LCD显示屏, 加快了其应用化进程. 相比于碳纳 米管和石墨烯需要通过与液态水中的离子相互作用
实现水能转化的特性, 这种水蒸发驱动发电的碳黑 薄膜可以转化不含离子的淡水水能, 具有更加广泛 的适用环境. 

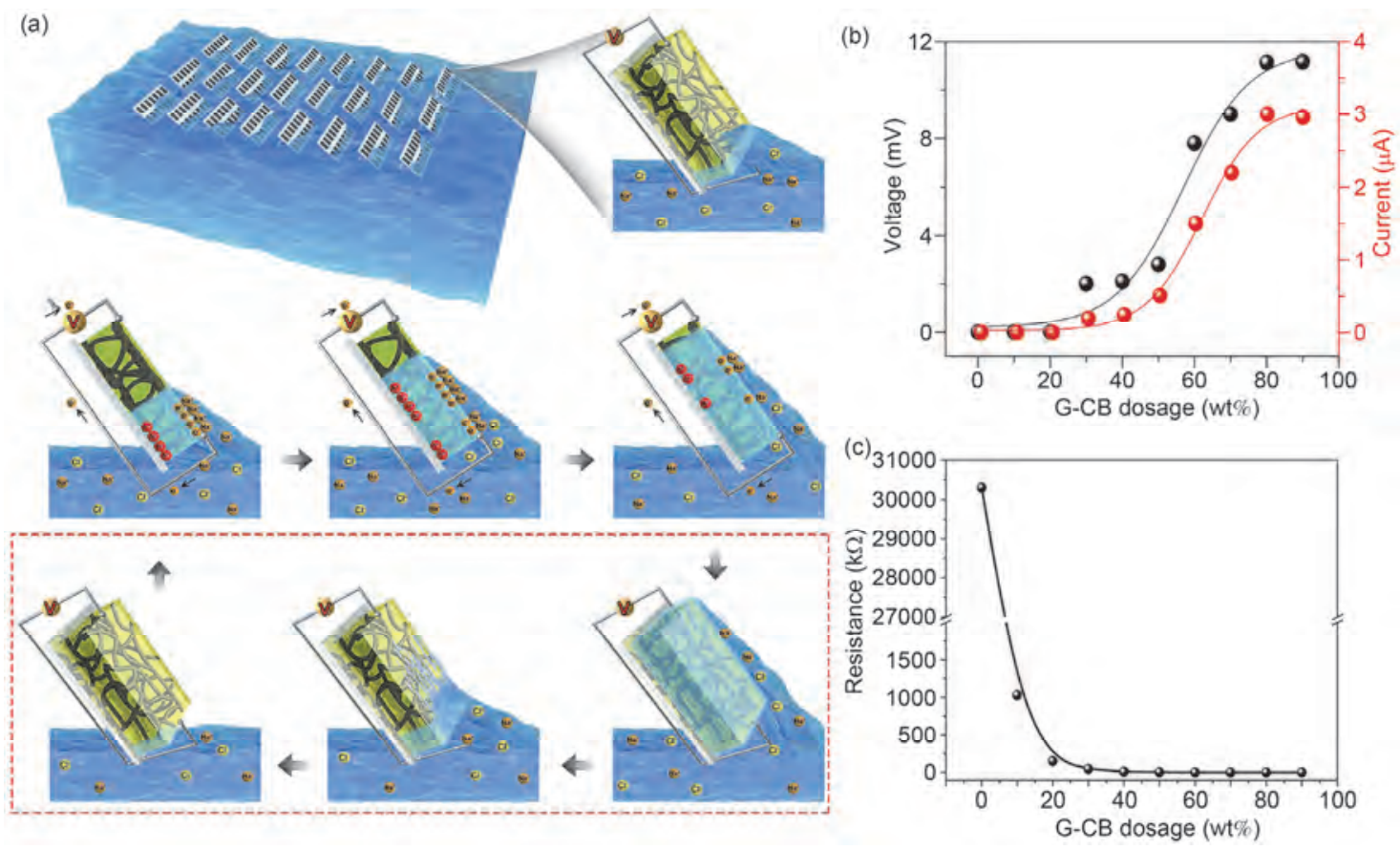

图 5 (网络版彩色)(a) 基于电动理论的薄膜类波浪能转化器件及在波浪冲刷过程中的电荷传输示意图; (b) 波浪能转化器件的电流和电压输 出与石墨烯-碳黑(G-CB)含量的关系曲线; (c) 波浪能转化器件的欧姆电阻与石墨烯-碳黑含量的关系曲线 [26]

Figure 5 (Color online) (a) Illustration of charge transfer during the process waving seawater onto film-type wave energy converter. (b) The plots of voltage and current as a function of G-CB dosage. (d) The resistance of G-CB/PU films at various G-CB dosages ${ }^{[26]}$

(a)

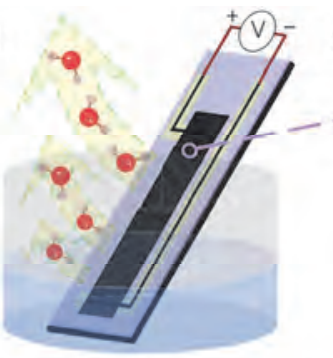

(b)

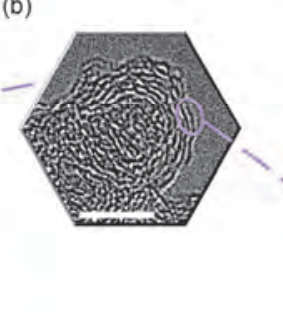

(c)

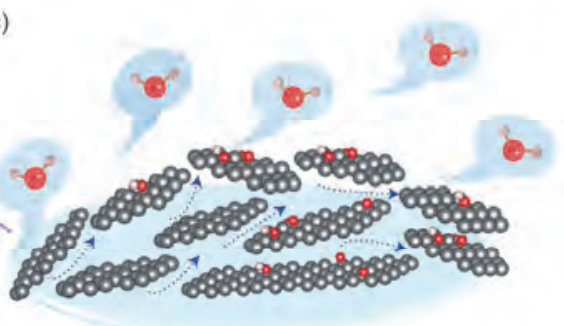

(d)

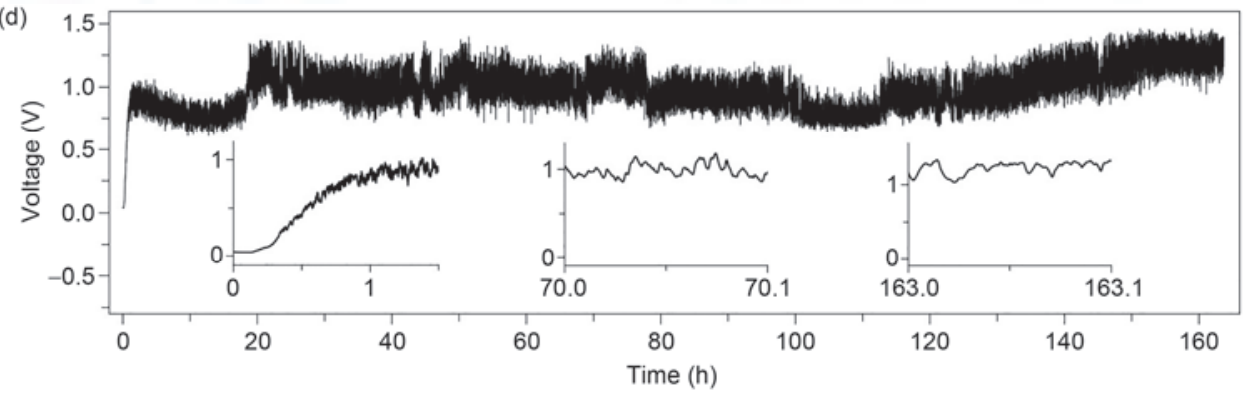

图 6 (网络版彩色)(a) 水蒸发诱导发电的器件结构示意图; (b) 碳黑纳米颗粒的高分辨率透射电子显微镜(HR-TEM)照片; (c) 水蒸发及水分子 在多孔碳黑薄膜中的流动过程; (d) 实验室条件(温度 $21.7 \sim 23.6^{\circ} \mathrm{C}$, 相对湿度 $53.5 \%$ 66\%)下水在碳黑表面蒸发产生的长时间电压输出图 ${ }^{[25]}$

Figure 6 (Color online) (a) Device structure diagram of water evaporation-induced power generator. (b) Typical HR-TEM image of carbon black nano-particles. (c) Schematic of water evaporation and flow of water molecules in porous carbon black films. (d) Output open-circuit voltage of the carbon black nanogenerators under fluctuating relative humidity between $53.5 \%$ and $66 \%$ and room temperature between 21.7 and $23.6^{\circ} \mathrm{C}$ for a long time ${ }^{[25]}$

包括一维碳纳米管、二维石墨烯、碳黑薄膜在内 的多种纳米碳材料都具有独特的水伏性质, 其能量
转换器件可以将各种形式的液态水能转化为电能, 虽然材料和器件的种类繁多, 但实现能量转化的主 
要原理可以归纳为两类: 一是由于固-液、气-液、固液-气界面处双电层边界移动造成电荷分布不均而产 生电势差, 这类电势主要包括盐溶液液滴在纳米碳 材料表面移动时产生的拖曳电势以及将碳纳米管、石 墨烯浸人/拔出盐溶液过程中产生的波动电势 ${ }^{[32,36,37]}$, 这类电势的产生需要依靠液体中离子与纳米碳材料 的相互作用, 即纳米碳材料对液体中阳离子的不断 吸附/解吸从而引起纳米碳材料表面载流子浓度变化 而产生脉冲式电信号, 电信号的方向与双电层边界 移动的方向和材料的亲疏水性质有关; 二是由于水 分子与碳层的相互作用而产生的电势差, 这类电势 的产生不需要液态水中富含阴、阳离子, 依靠水分子 与特殊结构的纳米碳材料相互作用产生持续的电输 出, 因此电信号也呈现出长时间内逐渐增大然后维 持不变的趋势, 但其具体的内在发电机理目前还不 完全清楚.

\section{2 水伏材料与器件对气态水能的转化}

\section{1 零维石墨烯量子点系}

石墨烯量子点是一类由单层或多层石墨烯片层 的径向尺寸小于 $20 \mathrm{~nm}$ 的零维纳米碳材料. 石墨烯量 子点因具有小尺寸、高比表面积和丰富的边缘位点而 表现出优异的光、电特性 ${ }^{[2,43]}$, 在光伏、催化、生物 成像和传感器等领域具有广泛的应用前景 ${ }^{[44 ~ 46]}$. 最 近, 北京理工大学曲良体课题组 ${ }^{[19]}$ 报道了一种以石 墨烯量子点为活性材料的高效水蒸气驱动纳米发电
机, 在对其进行电化学极化处理后, 该纳米发电机可 在相对湿度为 $70 \%$ 的环境下最高产生 $0.27 \mathrm{~V}$ 的电压, 接人负载后最佳电功率输出为 $1.86 \mathrm{~mW} / \mathrm{cm}^{2}$. 如图 7 所示, 经过电化学极化的石墨烯量子点器件内部产 生了含氧官能团的浓度梯度, 当器件暴露在水蒸气 环境时, 大量水分子被吸附在器件富含氧官能团一 端, 此时 $\mathrm{O}-\mathrm{H}$ 键断裂释放出 $\mathrm{H}^{+}$离子, 导致 $\mathrm{H}^{+}$离子局 部富集, 在浓度梯度的作用下, $\mathrm{H}^{+}$离子扩散到器件的 另一端并因此产生电压, 外电路中则体现为电子的 反方向运动; 当水分子于器件表面解吸时, 自由的 $\mathrm{H}^{+}$离子迁回与带负电的含氧基团重新结合, 产生了 相反方向的电信号; 随后, 被吸附的剩余水分子释 放, 石墨烯量子点器件回到初始状态, 从而完成 1 个 发电循环. 由于石墨烯量子点尺寸小、比表面积大且 含有大量含氧官能团, 因此水分子更容易被吸附在 器件表面, $\mathrm{H}^{+}$离子在器件内部的传输阻力小, 有利于 产生更大的电功率输出. 这种基于石墨烯量子点制 备的水蒸气驱动纳米发电机实现了对自然界中气态 水能的收集，不仅可以应用于人体呼吸发电等小型 灵活的发电装置, 也可以通过大规模集成捕获高湿 度地区的气态水能.

\section{2 二维碳黑薄膜系}

石墨烯量子点器件内部的含氧官能团浓度梯度 是器件两端能够产生电势差的根本原因, 与之相似, 在其他碳材料内部构建含氧基团的浓度差也可能实 现器件对气态水能的转化. 华中科技大学周军研究

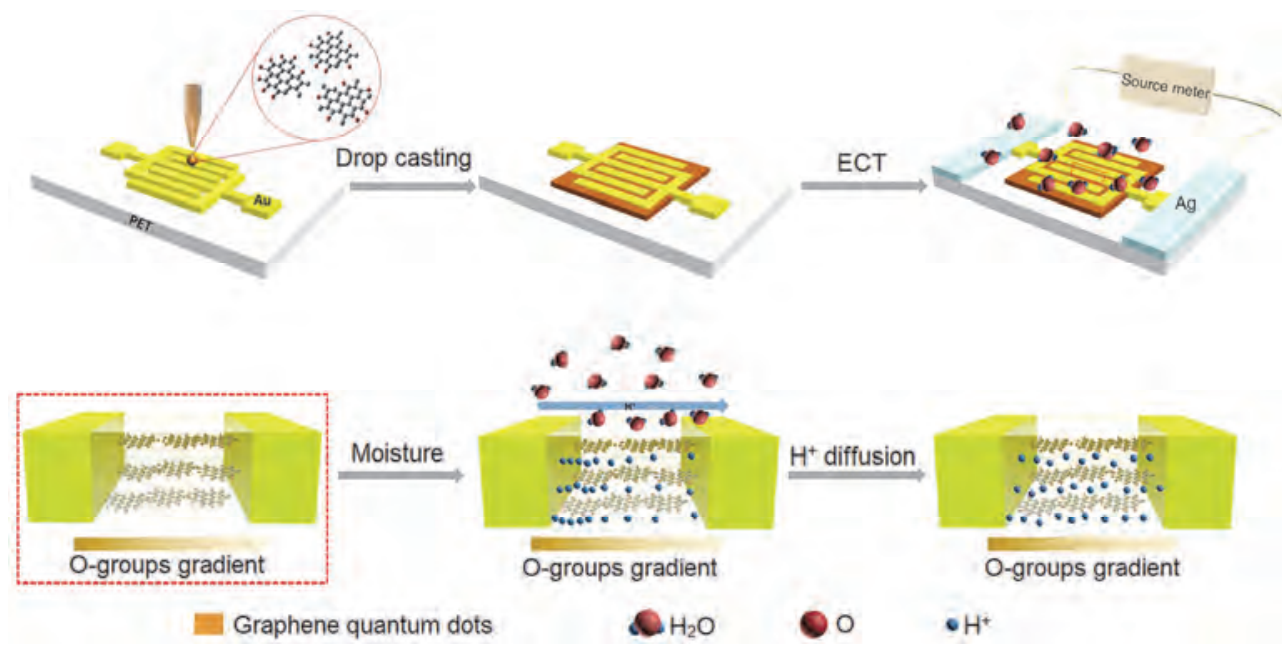

图 7 (网络版彩色)水蒸气驱动石墨烯量子点纳米发电机的器件结构及电荷传输示意图 ${ }^{[19]}$

Figure 7 (Color online) Schematic of device structure and charge transfer of water vapor-driven graphene quantum dot nanogenerator ${ }^{[19]}$ 
组 ${ }^{[22]}$ 开发了一种由水蒸气吸附驱动发电的多孔碳黑 薄膜, 通过等离子处理等手段使薄膜两端含氧基团 浓度产生差异(图8(b)), 将这种碳黑薄膜组装成器件 (图8(a), (b))置于高湿度环境(RH>83\%)时, 含氧基团 会吸附水分子并在原处释放 $\mathrm{H}^{+}$, 由于器件两端含氧 基团浓度差的存在, 碳黑薄膜中高含氧基团浓度一 端的 $\mathrm{H}^{+}$数量远远大于低含氧基团浓度的一段, 在碳 黑薄膜两端形成了明显的 $\mathrm{H}^{+}$浓度差; 在浓度差的作 用下, $\mathrm{H}^{+}$由高浓度端向低浓度段定向移动, 从而在外 电路中产生了相应的电信号. 在相对湿度 $>95 \%$ 的高 湿度环境下, 器件可以产生约 $68 \mathrm{mV}$ 的稳定电压信号 并且持续输出超过 $6 \mathrm{~h}$; 而没有经过处理, 两端没有 含氧官能团浓度差异的器件在同样条件下没有产生 任何电输出(图8(d)). 这种由水蒸气吸附驱动发电的 多孔碳黑薄膜不仅制备工艺简单, 而且可以在高湿
度环境下产生持续的电输出，对有效收集高湿度地 区蕴含的气态水能有着重要意义.

利用多孔纳米碳黑薄膜独特的水蒸发生电特性 及其在能源器件的电极领域的巨大应用潜力, 本研 究组 ${ }^{[47]}$ 设计了一种基于碳电极的无空穴全无极钙钛 矿太阳能电池器件, 巧妙地实现了器件对水蒸气能 和太阳能的同时捕获(图9). 碳黑电极由于具有负的 zeta电位, 会对水中 $\mathrm{H}^{+}$产生吸附作用, 被吸附的 $\mathrm{H}^{+}$与 碳膜中电子形成双电层结构, 蒸发产生的水蒸气流 在含有亲水基团的多孔碳膜内的运动导致双电层结 构中电子重新分布从而产生了电信号输出, 器件在 $80 \%$ 的相对湿度下可以获得 $0.35 \mathrm{~V}$ 的电压和 $0.45 \mu \mathrm{A}$ 的电流, 同时在标准太阳光照条件下获得 $9.43 \%$ 的光 电转换效率. 由于无机钙钛矿 $\mathrm{CsPbBr}_{3}$ 在高湿度环境 下的优异稳定性, 该器件在高效收集转化水蒸气能
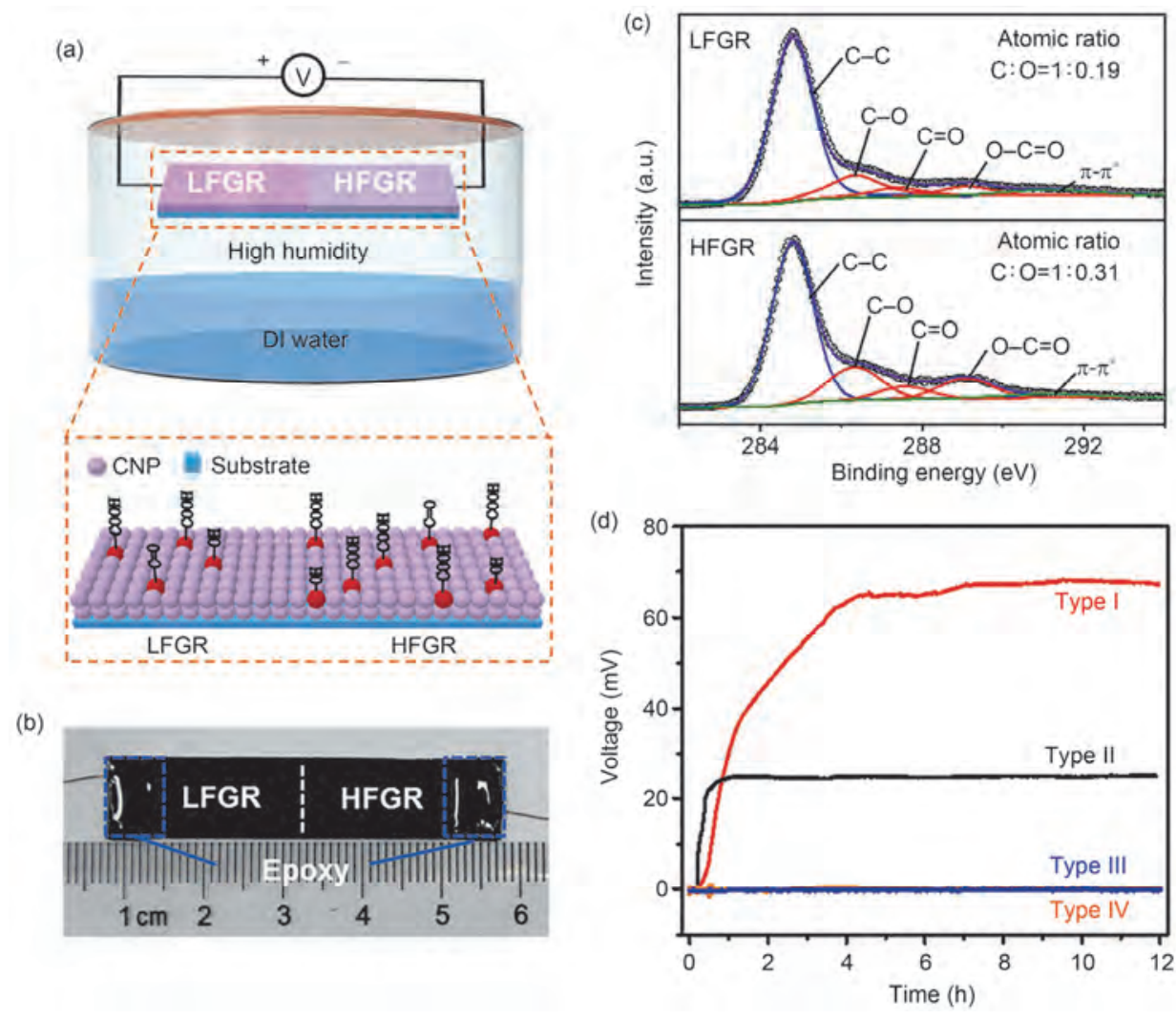

图 8 (网络版彩色)水蒸气吸附诱导发电的器件结构示意图(a)和器件照片(b); (c) 经过等离子功能化处理和未经处理的多孔碳黑薄膜X射线光 电子能谱分析(XPS)图谱; (d) 不同水蒸气吸附诱导发电的器件开路电压信号图. I, 样品一半进行等离子功能化处理; II, 样品一半进行酸功 能化处理; III, 样品全部进行等离子功能化处理; IV, 样品不做任何处理 ${ }^{[22]}$

Figure 8 (Color online) Device structure diagram (a) and picture (b) of water vapor absorption induced power generator. (c) XPS spectra of the plasma-functionalized and pristine porous carbon films (PCF). (d) Open-circuit voltage generated by vapor adsorption. Device types I, II, III, and IV correspond to the PCF sample with a half region functionalized by plasma, the sample with a half region functionalized by acid, the sample with the full region functionalized by plasma, and the sample without any plasma or acid treatment, respectively ${ }^{[22]}$ 

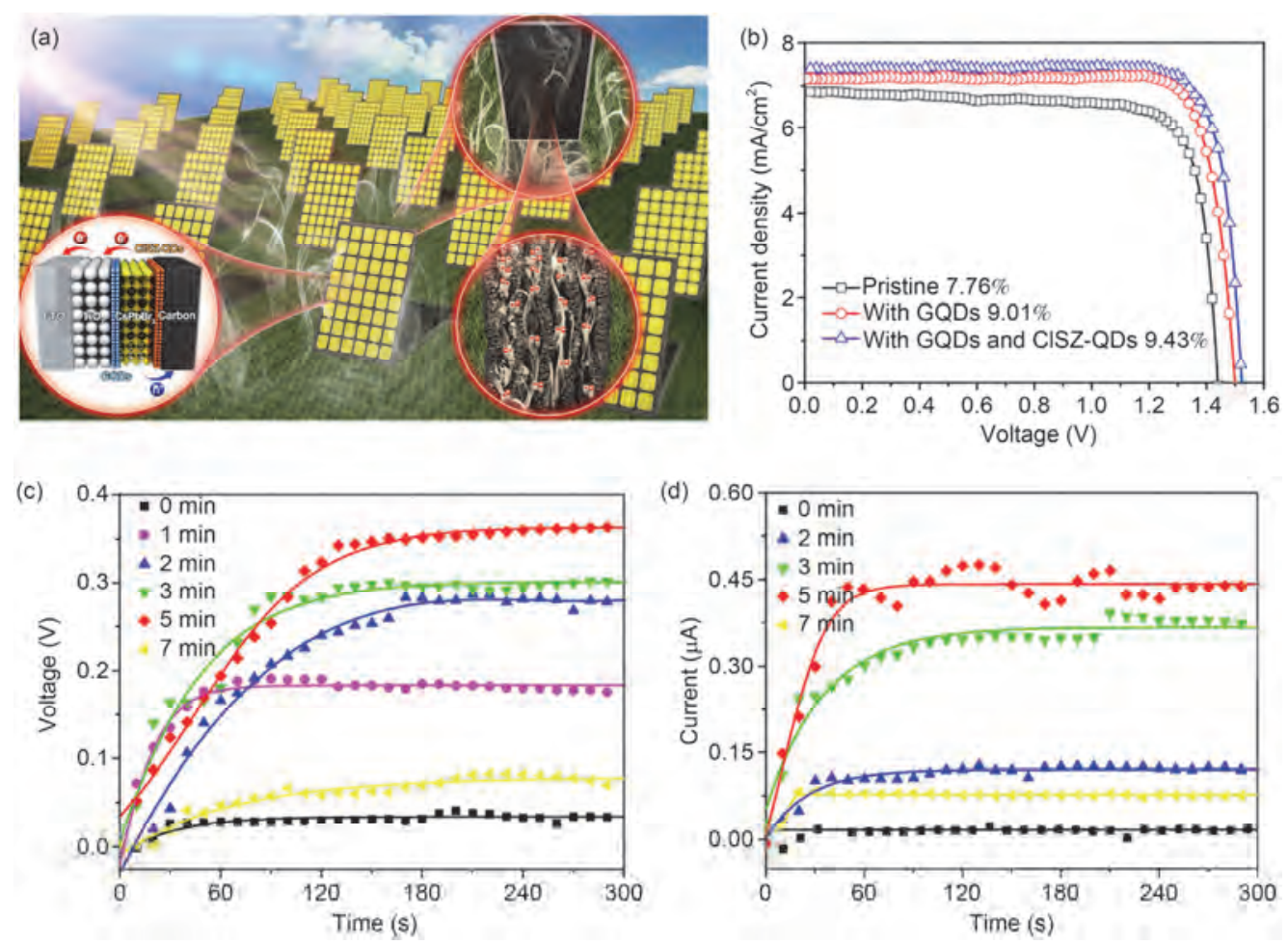

图 9 (网络版彩色)(a) 同时捕获太阳能和水蒸气能的全无机钻钛矿器件结构和电荷传输示意图; (b) 全无机钻钠矿电池的J- $V$ 曲线; 碳电极经 不同等离子处理时间后的水蒸气诱导电压(c)和电流(d)信号 ${ }^{[4]}$

Figure 9 (Color online) (a) The schematic diagram of charges transfer and all-inorganic perovskite solar cells for harvesting solar and water-stream energies. (b) Characteristic $J$ - $V$ curves of all-inorganic perovskite solar cells. The water-stream induced voltage (c) and current (d) outputs from carbon electrodes with different plasma treat time ${ }^{[47]}$

的同时完成了对太阳能的利用，这不仅有利于提高 器件在光照充足、水蒸发剧烈环境下的电能输出，同 时为多能集成转化器件的设计提供了新的思路.

\section{3 三维氧化石墨烯系}

氧化石墨烯相比于石墨烯具有更多的含氧基团 和更强的亲水性, 因此, 具有多孔结构的三维氧化石 墨烯有利于水分子在其内部的传输和相互作用, 在 捕获气态水能方面具有更大的应用潜力 ${ }^{[48 \sim 51]}$. 北京 理工大学曲良体研究组 ${ }^{[23]}$ 制备了一种超亲水的三维 氧化石墨烯结构, 通过电化学极化处理使其具有独 特的含氧基团浓度梯度(图10(e)), 当这种三位氧化石 墨烯薄片处于湿度较大的环境时, 水分子被吸附在 含氧基团浓度高的一端, $\mathrm{O}-\mathrm{H}$ 键断裂释放大量 $\mathrm{H}^{+}$离 子, $\mathrm{H}^{+}$离子由浓度高的一端向浓度低的一端定向移 动, 电子在外电路中反向移动产生电信号; 铝箔/三 维氧化石墨烯/铝簿的器件结构(图 10(a))既能保证水 分子与氧化石墨烯表面充分接触, 又能将电子传导 至外电路, 器件在相对湿度变化为 $75 \%$ 的环境下的
输出电压和电流密度分别为 $0.26 \mathrm{~V}$ 和 $3.2 \mathrm{~mA} / \mathrm{cm}^{2}$.

能够实现对气态水能转换的纳米碳材料目前已 经涵盖了量子点、碳黑、氧化石墨烯薄膜以及三维氧 化石墨烯多孔结构等多种纳米碳材料, 但其发电原 理有一定的相似性，电势大多依靠不同浓度的含氧 基团对水分子的吸附和由此出现的载流子浓度差产 生; 但是, 通过部分等离子处理的多孔碳黑薄膜在高 湿度下产生的电信号形态与石墨烯量子点、氧化石墨 烯等不同, 前者在维持高湿度不变的环境中可以产生 持续的电信号输出, 而后者电信号的产生需要外界环 境中湿度的变化来完成水分子吸附/解吸的循环, 产 生的电信号则呈现为瞬时的脉冲形, 这可能与不同纳 米碳材料的结构差异和官能团引人方式的不同有关.

\section{3 总结和展望}

自2003年发现碳纳米管在水流响应下产生流动 电势以来，利用纳米碳等水伏材料将自然界中广泛 存在的水能转化为电能成为了人们的研究重点. 通 过材料优选和器件设计, 已经实现了对包括水蒸气、 
(a)
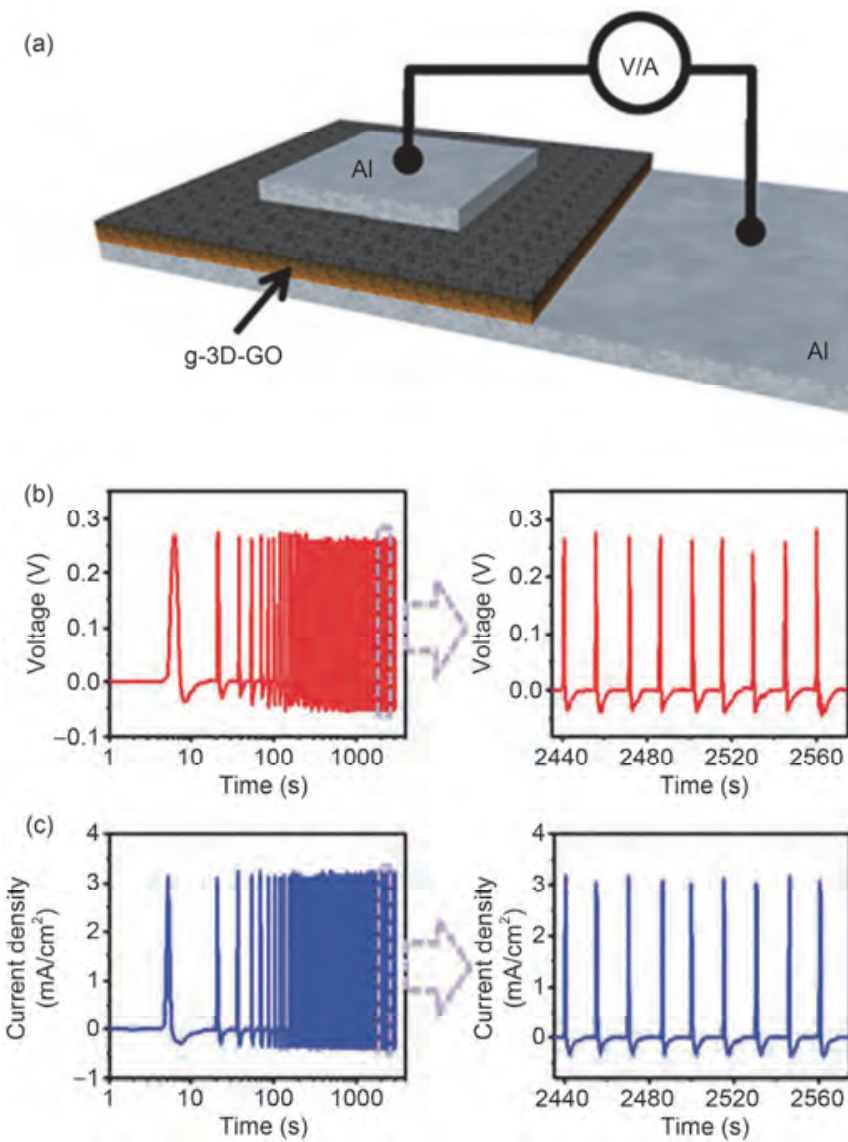
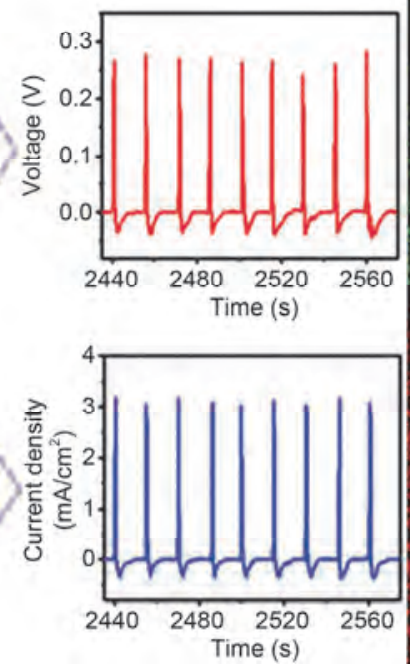

(d) $\varepsilon$

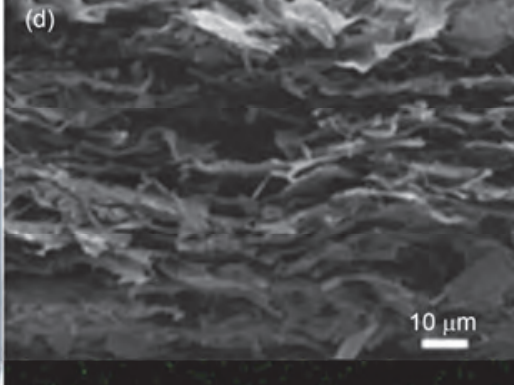

(e)

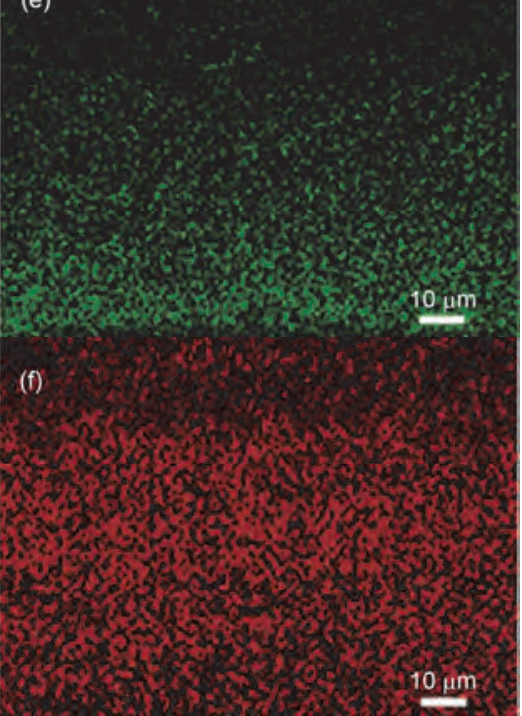

图 10 (网络版彩色)(a) 基于三维氧化石墨烯的水蒸气驱动发电器件结构; (b) 器件对周期间歇性湿度变化( $\Delta \mathrm{RH}=75 \%$ )的电压响应; (c) 器件对 周期间歇性湿度变化 $(\Delta \mathrm{RH}=75 \%)$ 的电流响应; (d) 三维氧化石墨烯的扫描电子显微镜(SEM)照片; 三维氧化石墨烯结构的氧(e)和碳(f)元素分 布 ${ }^{[23]}$

Figure 10 (Color online) (a) Device structure diagram of water vapor driven power generator based on three-dimensional graphene oxide. (b) Voltage output signals in response to the $\mathrm{RH}$ variation $(\Delta \mathrm{RH}=75 \%)$. (c) Current output signals in response to the $\mathrm{RH}$ variation $(\Delta \mathrm{RH}=75 \%)$. (d) $\mathrm{SEM}$ image of three-dimensional graphene oxide. Oxygen (e) and carbon (f) distribution in three-dimensional graphene oxide structure ${ }^{[23]}$

雨滴、水流、波浪在内的多种水能形态的转化, 并成 功驱动了小型用电装置 ${ }^{[52 ~ 56]}$. 但是, 目前对于水伏 材料与技术的研究还处在初期阶段, 要实现其在实 际环境中的应用仍存在几个关键问题亟需解决：(1) 输出功率小, 某些器件实现水能转化的机理还不完 全清楚, 不利于器件性能的进一步提升; (2) 环境要 求苛刻, 目前器件工作多在实验室模拟下的较理想 环境中进行, 由于实现水能转化的过程大多需要水 与器件表面直接接触, 实际环境中的长期稳定性难 以保证; (3) 难以实现规模化集成应用, 这主要受限 于集成技术的欠缺和昂贵的原材料、金属电极成本.

尽管如此, 水伏材料及能量转换器件仍因为转 化效率高、适用环境广泛、器件结构简单等优势成为 极具前景的绿色能源捕获技术: 一方面, 微小的体积
和高度的灵活性可以使其实现呼吸机、传感器等小型 设备的供电; 另一方面, 高效的转化效率和简单的结 构有利于器件实现大规模集成后的大功率发电和海 岛、浮标等远海设施设备的长期自供电. 针对目前纳 米碳材料类水伏材料与器件输出功率小、环境适应性 差、成本高昂的问题, 可通过以下途径尝试解决: (1) 优化纳米碳材料结构, 增加其与离子、水分子接触位 点; (2) 降低材料内阻, 减小载流子传输损耗; (3) 掺 杂功能性组分, 提高水能转化过程中材料内部载流 子浓度; (4) 将纳米碳材料与光电材料、压电材料等 有机结合, 通过对光能、水中机械能等多种形式能量 的转化提高器件的电输出; (5) 开发具有相似水伏性 质(表面富电子、对阳离子有吸附作用)且成本低廉的 新型水伏材料, 如导电聚合物、合金等. 


\section{参考文献}

1 Song S, Xue Y, Feng L, et al. Reversible self-assembly of terpyridine-functionalized graphene oxide for energy conversion. Angew Chem Int Ed, 2014, 53: 1415-1419

2 Jiao Y, Zheng Y, Jaroniec M, et al. Design of electrocatalysts for oxygen- and hydrogen-involving energy conversion reactions. Chem Soc Rev, 2015, 44: 2060-2086

3 Xiong J Y, Han C, Li Z, et al. Effects of nanostructure on clean energy: Big solutions gained from small features. Sci Bull, 2015, 60: 2083-2090

4 Li H, Xiao Z, Ding L M, et al. Thermostable single-junction organic solar cells with a power conversion efficiency of 14.62\%. Sci Bull, 2018, 63: 340-342

$5 \mathrm{Su}$ Y, Wen X, Zhu G, et al. Hybrid triboelectric nanogenerator for harvesting water wave energy and as a self-powered distress signal emitter. Nano Energy, 2014, 9: 186-195

6 Lin Z H, Cheng G, Lin L, et al. Water-solid surface contact electrification and its use for harvesting liquid-wave energy. Angew Chem Int Ed, 2013, 125: 12777-12781

7 Scruggs J, Jacob P. Harvesting ocean wave energy. Science, 2009, 323: 1176-1178

8 Evans D V. Power from water waves. Annul Rev Fluid Mech, 1981, 13: 157-187

9 Falnes J, Perlin M. Ocean waves and oscillating systems: Linear interactions including wave-energy extraction. Appl Mech Rev, 2003, 56: $1-32$

10 Liu Z, Zheng K, Hu L, et al. Surface-energy generator of single-walled carbon nanotubes and usage in a self-powered system. Adv Mater, 2010, 22: 999-1003

11 Chen M J, Yu F, Hu L J, et al. Recent progresses on the new condensed forms of single-walled carbon nanotubes and energy-harvesting devices. Chin Sci Bull, 2012, 57: 181-186

12 Liu J, Dai L, Baur J W. Multiwalled carbon nanotubes for flow-induced voltage generation. J Appl Phys, 2007, 101: 0643121

13 Dhiman P, Yavari F, Mi X, et al. Harvesting energy from water flow over graphene. Nano Lett, 2011, 11: 3123-3127

14 Zhao F, Cheng H, Zhang Z, et al. Direct power generation from a graphene oxide film under moisture. Adv Mater, 2015, 27: 4351-4357

15 Wang Y L, Duan J L, Zhao Y Y, et al. Self-powered PEDOT and derivate monoelectrodes to harvest rain energy. Nano Energy, 2017, 41: 393-300

16 Tang Q W, Duan Y Y, He B L, et al. Platinum alloy tailored all-weather solar cells for energy harvesting from sun and rain. Angew Chem Int Ed, 2016, 128: 14412-14416

17 Ghosh S, Sood A K, Kumar N. Carbon nanotube flow sensors. Science, 2003, 299: 1042-1044

$18 \mathrm{Xu} \mathrm{Y}$, Chen P, Zhang J, et al. A one-dimensional fluidic nanogenerator with a high power conversion efficiency. Angew Chem Int Ed, 2017, 56: 12940-12945

19 Huang Y, Cheng H, Shi G, et al. Highly efficient moisture-triggered nanogenerator based on graphene quantum dots. ACS Appl Mater Interfaces, 2017, 9: 38170-38175

20 Zhao Y, Song L, Deng K, et al. Individual water-filled single-walled carbon nanotubes as hydroelectric power converters. Adv Mater, 2008, 20: 1772-1776

21 Yin J, Li X, Yu J, et al. Generating electricity by moving a droplet of ionic liquid along graphene. Nat Nanotechnol, 2014, 9: 378-383

22 Liu K, Yang P, Li S, et al. Induced potential in porous carbon films through water vapor absorption. Angew Chem Int Ed, 2016, 55: 8003-8007

23 Zhao F, Liang Y, Cheng H, et al. Highly efficient moisture-enabled electricity generation from graphene oxide frameworks. Energy Environ Sci, 2016, 9: 912-916

24 Tang Q W, Wang X P, Yang P Z, et al. A solar cell that is triggered by sun and rain. Angew Chem Int Ed, 2016, 55: 5243-5246

25 Xue G, Xu Y, Ding T, et al. Water-evaporation-induced electricity with nanostructured carbon materials. Nat Nanotechnol, 2017, $12: 317-321$

26 Tan J, Duan J L, Zhao Y Y, et al. Generators to harvest ocean wave energy through electrokinetic principle. Nano Energy, 2018, 48:128-133

27 De Volder M F, Tawfick S H, Baughman R H, et al. Carbon nanotubes: Present and future commercial applications. Science, 2013, 339: 535-539

28 Král P, Shapiro M. Nanotube electron drag in flowing liquids. Phys Rev Lett, 2001, 86: 131-134 
Xu T, Din Small, 2018, 14: 1704473

52 Zhao F, Wang L, Zhao Y, et al. Graphene oxide nanoribbon assembly toward moisture-powered information storage. Adv Mater, 2017, 29: 1604972

53 Cheng H, Huang Y, Cheng Q, et al. Self-healing graphene oxide based functional architectures triggered by moisture. Adv Funct Mater, 2017, 27: 1703096

54 Son M, Park H, Liu L, et al. Thin-film nanocomposite membrane with CNT positioning in support layer for energy harvesting from saline water. Chem Eng J, 2016, 284: 68-77

55 Zhong H, Wu Z, Li X, et al. Graphene based two dimensional hybrid nanogenerator for concurrently harvesting energy from sunlight and water flow. Carbon, 2016, 105: 199-204

56 Zhong H, Xia J, Wang F, et al. Graphene-piezoelectric material heterostructure for harvesting energy from water flow. Adv Funct Mater, 2017, 27: 1604226 


\title{
Watervoltaic materials and energy conversion device based on carbon nanomaterials
}

\author{
Jin Tan ${ }^{1}$, Qunwei Tang ${ }^{2 *} \&$ Benlin $\mathrm{He}^{1}$ \\ ${ }^{1}$ School of Materials Science and Engineering, Ocean University of China, Qingdao 266100, China; \\ ${ }^{2}$ Institute of New Energy Technology, Jinan University, Guangzhou 510632, China \\ * Corresponding author, E-mail: tangqunwei@jnu.edu.cn
}

Harvesting renewable energy and realizing its transformation into electricity is one of the effective ways to solve energy crisis and environmental problems. Hydroenergy has been considered as a promising energy with enormous development potential and application value because of its great advantages of large reserves, wide distribution, and environmentally friendly. Nowadays, the development and utilization of hydropower resources mainly rely on dams, generators and other steel facilities to convert mechanical energy to electricity, with inherent defects of inefficiency and damage to the ecological environment. Therefore, developing new types of watervoltaic materials and devices with diverse application environments, high energy conversion efficiency and low power generation costs is an effective improvement and complement to current water energy utilization condition. Carbon nanotube flow sensor reported by Shankar Ghosh in 2003 first proved the property of carbon nanotube that it can generate electricity in floating water, promoting the research of carbon nanomaterials for power generation in fluids. In the following years, several kind of carbon nanomaterials with different dimensions including carbon nanotube, graphene, et al. were successively confirmed that they have similar character to convert hydroenergy to electricity. Various theories including phonon dragging were proposed to explain this phenomenon as well as the form of electric double layer (EDL) and electrokinetic theory fit it reasonably both in charge transfer and electrical output. Related devices were also designed and assembled to convert energy in liquid water, such as ion water drops, saline solution, et al., to electricity, increasing electrical output from initial a few millivolts to a few volts with a small number of devices in series, which is enough to drive small loads. Subsequently, carbon nanomaterials/polymer conducting composite film was designed to harvest energy from real raindrops and seawater waves, making a great progress of watervoltaic materials and devices in practical application. In addition to converting energy in liquid water, devices based on carbon nanomaterials with different dimensions including quantum dots, nano-carbon film and graphene oxide can harvest energy in water vapor and water evaporation, making it possible to collect and convert energy in gaseous water in nature. Unique structures of holes, elemental concentration gradient, et al. were considered to make contributions to capture water molecule and transfer charges, resulting of the electrical output between electrodes. The combination of nano-carbon electrode and all inorganic perovskite solar cells realizes simultaneous collection of water vapor energy and solar energy, making great significance for implementing multi-energy integration of devices. Since carbon nanomaterials were confirmed to be able to convert extensive water energy in natural into electrical energy, different materials and devices were designed and manufactured to increase the electrical output, improve stability and reduce power generation costs. However, there are also challenges including unclear working mechanism, high environmentally demanding and difficulty to integrate devices on a large scale need to be overcomed in the future. Despite this, watervoltaic materials and energy conversion devices have become promising green energy capture technologies due to their high conversion efficiency, wide application environment, and simple device structure. Improving usability is one of the directions of watervoltaic devices development.

watervoltaic materials and devices, carbon nanomaterials, streaming potential, energy harvest, energy conversion doi: 10.1360/N972018-00377 